\title{
Applying Feminist Ethics of Care to Nursing Practice
}

\section{Brenda Green}

First Nations University of Canada, 1301 Central Avenue, Prince Albert, Saskatchewan, Canada

\begin{abstract}
Through acculturation and socialization, caring involves both gendered and socially diverse patterns of understanding and behaving in the world. As a result, the implications for care are embedded in the personal and social values and experiences associated with gender, power, and politics. The general ethos of this paper will explore a feminist care ethic that emerged from the work of Carol Gilligan. This standpoint offers particular peripheral advantages as a feminist theorists' critique of caring includes the critical examination of relationships from the position of people who have systematically been excluded from power. Although this perspective is theoretically challenging, it offer insights to the significance of caring for the other, the self and the community.
\end{abstract}

Keywords: Feminist; Feminine; Masculine; Ethics of care

\section{Introduction}

Care is a broad topic that is difficult to define. Many critics and advocates of care theories are concerned with the lack of conceptual and practical clarity in defining care. This theoretical ambiguity has resulted in describing care as many different mental states, behaviours and meaning [1]. Although individual knowledge and experiences in caring remain implicit in nursing practice, more attention needs to focus on the theoretical underpinnings of nursing epistemologies. The goal of research in caring science is to establish theoretical foundations that can be utilized to describe and explain the meaning of caring and the conditions for a caring practice [2].

Although, historically the field of philosophy has positioned care as a moral duty, an obligation or as a trait of justice, this standpoint has primarily featured a masculine perspective. New conceptualizations of care have evolved which emphasize the centrality of relationships in social and gendered lives [3-6]. Nursing practices involve knowledge of and relationships with diverse cultures and societies. As a result caring involves the gendered, cultural and socially diverse patterns of understanding and behaving in the world. Therefore the implications for care are embedded in the personal and social values and experiences associated with culture, gender, power, and politics.

One perspective of care is concerned with feminist ethics. This concept challenges the philosophic foundations of the justice theory (masculine) and argues that the notion of care is best understood from a perspective that focuses on the associations between people and on the contextual experiences within these relationships [7]. A feminist approach questions power relations and issues of domination within the institution, the academy and within nursing practice.

Gilligan's [4] standpoint offers particular peripheral advantages as a critique of caring as this concept includes the critical examination of relationships from the position of people who have systematically been excluded from power. This concept is relevant in the nurse-patient relationship as those who seek health services are in a vulnerable and dependent position. Feminist standpoint argues that the experiences of those who are marginalized can provide a raised awareness on social issues providing valuable insights into how care is rendered in society [8].

As nursing practice is embedded in relationships and is dependent on the political structures for support, care then becomes a political concept. The purpose of this paper is to explore a feminist ethic of care and argue that including a feminist standpoint in the construction of nursing foundations would benefit both teaching and theoretical concepts of caring practice.

\section{Defining Care}

Relationships have been cited as the fundamental intellectual, theoretical, and heuristic base that forms the foundation in nursing science. For example, care can be viewed as a bond or contract that involves the commitment to alleviating another's vulnerability [9]. Leininger [10] suggests caring is based on interdependent relationships between people illuminating the essence, nature, expression, and the function of caring and its relationship to others and Sumner [11] suggests that caring in nursing is primarily a communicative action. Bowden [12] argues that care is the ongoing relational practices that includes concern and responsibility and is necessary for the development of personal, physical, psychological and moral integrity. This definition suggests that the nature of care is more than simply a response to an explicit expression of need and may appeal to a set of moral imperatives that are often overlooked by many theorists [13]. Instead, care is better understood as relationships that are constructed in culture and society, and shaped by political and structural environments.

\section{Culture and Sociality in Nursing}

As culture is socially constructed, the rituals that are embedded in cultural norms, customs and traditions determine the care of the community, social group or individual [14]. Although Ruddick [15] argues that women predominate in nurturing roles and service occupations, these role positions women to acquire altruistic, relational, and maternal moral dispositions, while men, on the other hand, occupy roles in the competitive public sphere, are more oppositional, autonomous, and self-interested. A feminist standpoint of care seeks to organize social and moral theory around constructs of care by centering attention on the experiences and practices of cultural groups, and challenges dominant masculine values such as autonomy, conflict and power, nursing science could benefit from ideals of partiality, relationship, independence, and sociality.

Caring must also give rise to social action [7]. The resilience of the association between caring and action is an increasingly prominent

Corresponding author: Brenda Green, First Nations University of Canada 1301 Central Avenue, Prince Albert, Saskatchewan, Canada, E-mail: bgreen@firstnationsuniversity.ca

Received Novemer 10, 2012; Accepted May 07, 2012; Published May 09, 2012

Citation: Green B (2012) Applying Feminist Ethics of Care to Nursing Practice. J Nurs Care 1:111. doi:10.4172/2167-1168.1000111

Copyright: (c) 2012 Green B. This is an open-access article distributed under the terms of the Creative Commons Attribution License, which permits unrestricted use, distribution, and reproduction in any medium, provided the original author and source are credited. 
theme in feminist thought that focuses on the importance of difference. Within this perspective, approaches to understanding moral situations, defining self-concepts, choosing goals and roles, and guiding behaviour, are informed by and based upon dispositions and the motives of caring [7].

Feminist perspectives that advocate for the recognition of women's differences, views it as important for women to assert their distinctiveness in response to the social and cultural patriarchal norms, categories, and practices that dominate the construction of women's gender identity. The patriarchal construction of women's gender, acts to obscure women's distinctiveness in a way that leads them to become alienated from themselves [4]. However, an authentic reconstruction of the female gender must be solidly grounded in women's own experiences and self-perceptions that are not dominated by male interests.

\section{Feminism in Nursing Politics}

Along with a specific focus on gender relations, feminist theory identifies the structurally organized inequities of power and the often invisible workings of micro-politics that reinforce these structures. Feminist thinking, supported by post-colonial and post-structural theorists, focus on inequality that may accompany such concepts as race, gender, class and has illuminated how formal institutions as justice, health and welfare, have reinforced and reproduced constraining structural forms that restrict the development of empowering communal bonds.

Contemporary views of gender, knowledge and privilege which are grounded in power relations that are socially constructed can be both learned and unlearned. As a result knowledge and privilege can be unlearned. Consequently contemporary understandings of a feminist ethic of care is argued to be more inclusive than the traditional (moraljustice) perspective as it provides a theoretical rational for viewing caring as arising from a social position that all people can learn and utilize [16].

These cultural and social factors influence the values, beliefs and ways of living and provide the general pattern for caring. As caring is expressed differently in diverse and distinctive cultures, caring is formed by cultural processes and meaning [17,18]. Eagleton [19] suggests that culture highlights philosophical questions about freedom and determinism, change and identity, the given and the created. Culture also encompasses a series of meanings which constantly change over time and are in constant flux.

\section{Feminist Perspective of Care}

Additionally, the literature often relates similarities between feminist and feminine care ethics, however there are key philosophical differences between these two concepts. Houser, Wilczenski and Ham [20] suggest that feminism ideology includes two primary streams of "woman centered" approaches which are relevant to care ethics: the feminine and the feminist. 'Feminine' refers to the exploration for women's unique voice and advocates for an ethic of care. 'Feminist' refers to the resistance against male domination and advocates for equal rights. Both approaches seek to validate the importance of experience, understand the destructiveness of oppression, and eliminate gender and social inequality [20].

This caring perspective reflects concerns with feelings, relationships, and individual needs. A feminine ethic of care argues that responsibility develops from an individual's feeling of interconnectedness with others and reflects the role that these connections and relationships with others play in ethical decision-making. Central assumptions of feminine ethics are that women are similar enough to share a common perspective that is rooted in the biological capacity and expectation of motherhood that includes characteristically feminine traits such as compassion, empathy, nurturance, and kindness. Care ethics are not uniquely feminine, as men may also exhibit strong tendencies to care. Other factors of social identity, such as ethnicity, class and sociality influence the correlation of gender to care. Nonetheless, care has pervasively been assumed to be a symbolically feminine trait and perspective.

The characteristics most associated with caring as an ethical perspective are responsiveness, sensitivity to others, acceptance, and relatedness. Responsiveness to others includes responding to others to acknowledge value, and affirm them, while also being careful to listen to and observe others to understand their behavior. Sensitivity to others means taking care to identify and attend to others needs, desires, and perspectives, which is fundamentally about validating others. Acceptance entails allowing people to feel psychologically safe, or free to communicate their wants, feelings, needs, and beliefs. Finally, relatedness emerges from the care-givers view of the self as connected to or through interdependence with others. This sense of interdependence requires a caregiver to act cooperatively or in a relationship with others [16].

A distinctive view of caring relates interpersonal relationships are based in responsibility, such as the mother/child relationship and the concept of mothering [21]. Mothering involves practices that are constructed of inherent cultural qualities, shared goals, demands, procedures, and patterns of discourse. Ruddick [21] relates that mothering is a condition of maternal thinking that is retrieved as a response to demands and that these demands are necessary to "preservation, growth and social acceptability".

Although feminine and feminist care ethics are two separate, however overlapping theoretical concepts, as they both examine relationships as the core of care. However, the work of Gilligan [4] reshapes concepts of caring motives. Gilligans' feminist ethic of care argues that relationships and not responsibilities are the core variable of care. Gilligan also suggests that the masculine care response is embedded in social and cultural norms and constitutes deliberate processes of power that determine women's role in society. A feminist ethic of care is determined by the role that critical inquiry plays in the empirical and symbolic association between women and care, and is further concerned for the power-related implications of this association. Jaggar [22] characterizes a feminist ethic as one which exposes masculine and other biases in moral and care theory; understands individual actions in the context of social practices; illuminates differences between women; provides guidance for private, public, and international issues; and treats the experiences of women respectfully and critically.

\section{Feminist Ethics of Care in Nursing Practice}

Feminism is political positioning. It involves a commitment to material and social change and aims to produce useful knowledge that will make social and individual differences. Feminist research is political in standpoint, gendered in focus, reflexive in process and transformative in outcome [23]. Therefore, a feminist stand point focuses on the dynamics of relationships that recognizes the significance of institutional and social structures of power. The power structure that function within formal institutions and gendered divisions of labor, provide theoretical insights that illuminate and reinforce unjust inequities that are assigned as masculine and feminine. As nursing theory is interested in patterns of oppression, it is also concerned with domination and subordination, such as racism and classism [24]. 
For Gilligan, women exemplify care, which is an important moral characteristic. However Gilligan advocates for inclusive morality, one that strengthens relationships and solves problems without resorting to the binding authority of rules and principles.

Gilligan suggests the ethic of care is rooted in the moral frameworks of responsibility and relationships rather than rights and rules and that any care orientation is inseparable from contextual circumstances rather than being a formal and abstract system of thought. Additionally, care is grounded in the daily activity of life rather that a set of universal principles [13].

Halwani [25] suggests that we give equal weight in our moral deliberations to the like interests of all those affected by our actions suggesting that responding to the needs of our loved ones, claims partialism or discrimination, in our care to others. Although partialism seems arbitrary, it does assign greater importance to the protection of one's own interests and to the interests of those we care about, over the protection of the welfare of others, particularly those who are strangers.

An impartialist perspective also suggests preference. However this action is warranted on the grounds of utility and usefulness. Impartiality argues that people are motivated and morally obligated to respond to the vulnerability of other persons and suggests involves considerations of care for a particular person within a social context [26].

The partialist-impartialist debate is an important component of care theory as it forms the bases to determine if care is obligatory (responsibility to those in a relationship) or a duty (a functional and practical service to all). In nursing practice, these moral judgments abide by the principles, rights and duties without consideration of specific social circumstances [27] as morality is framed within universal, abstract principles that are rationally ascribed through nursing code of ethics and behaviors.

The problem arises when the contextual variables which allocate caring ethics as compassion, advocacy, and respect, are defined in quantifiable positions. Halwani [25] suggests it is impossible to conceptualized care in terms of context-free features. The fundamental difficulties with the partialist-impartialist debate is that descriptions of human caring capacities are abstracted from everyday realities and experiences, and therefore science cannot treat aspects of personhood, life-worlds or humanism the same way as it approaches the organicbiological being.

\section{Autonomy and Individualism in Nursing Practice}

Respect for autonomy or respect for persons has tended to be the leading principle of both moral and nursing ethics. However this principle which has historically been rooted in the liberal moral and political tradition of the masculine perspective lacks the ethical justification of actions or practices that strongly depend on the free decisions (impartiality) of individuals, i.e. an action or practice can only be ethically justified when undertaken without any coercive influence and entered by free and informed agreement. In nursing practice, two essential conditions exist: liberty, specifying the independence from controlling influences; and agency, referring to the capacity for intentional action [28]. Additionally Chirkov [29] argues that autonomy stems from a constructionist position and is a moral value that results from social production as a network of meanings and practices of a particular society and culture. Therefore issues of autonomy cannot be generalized across populations or within specific settings such as hospitals and communities.

\section{Relationships}

Care theorists emphasize human interdependence and connectedness. As a result, human beings respond to emotional and psychological needs that can only be fulfilled through relationships. Care theorists suggest the notion of relational autonomy, is central to developing one's personal identity and personal autonomy [30].

Feminist positions suggest that relationships are conceived within interpersonal and social contexts. A person's social environment and the personal relationships maintained within these environments impacts on autonomy. Human beings do not exist in complete isolation from others. Feminism stresses social embeddedness which includes the identity-forming influence of others, the significance of intimate relationships, deep attachments, and the important role that social systems (e.g. language and culture) play in an individuals' world [3133]. Feminist theory challenges the dominance of the individualistic perspective and alternatively argue that relationships- specifically, growth-fostering relationships- are a central human necessity. In other words, people need connection [34,35].

Caring in nursing practice is a relational experience between two people, and these relationships provide the basis for obligations and concerns (i.e. friends, patients, coworkers, family). Most nursing relationships with patients are asymmetrical, indicating one person remains the cared-for and is dependent on the carer (i.e. teachers and students, nurses and patients, parents and children). Some of these relationships vary in intimacy and intensity depending on the needs and context of the relationship.

Therefore, the context of the relationship holds particular importance as a place for the construction of care in nursing practice. Christman [33] argues that it is necessary to examine the different connotations and implications of relational and social interactions given the particular motivations to maintain the relationship. For example, a 'relational' interaction expresses the need to underscore interpersonal dynamics as components of autonomy, including the contexts of the caring relations, interpersonal dependence, and intimacy. 'Social' accounts imply, a broader view, where various other kinds of social factors; institutional settings, cultural patterns, political factors, may all come into play [30]. However, mutuality is a fundamental aspect of healthy, growth-promoting caring relationships, and is more than equality, reciprocity, and intimacy. Mutuality suggests a way of being-in relation to include the whole person and refers to a relational attitude, orientation, or stance [30]. Each person can present feelings, thoughts, and perceptions in the relationship and can move with and be moved by these feelings, thoughts, and perceptions of the other. Mutuality that influence, impact, and respond characterize such relationships, and are viewed as a dynamic processes within healing relationships [30].

Nurses can benefit from these relationships as they move from disconnection (a distant and indifferent nurse) to mutual connection that provides each person with a sense of personal authenticity as well as a sense of "knowing" or "seeing" the other. This experience of mutual empathy requires that each person have the capacity for empathic connecting. Empathy is a complex, highly developed ability to join with another at a cognitive and affective level without losing connection with one's own experience [30]. Openness to growth through empathic joining within the relational process is fundamental to nursing practice [36]. As such "power-with-others," is distinguished from "power-over" others, which has been the traditional structure of health care relationships, where one person (or group of persons) has been dominant and the other subordinate (patient or client). 


\section{Conclusion}

This paper explored the position of feminist care theory as necessary components to a caring nursing practice. Care must be understood and reflected on in relation to its place in the dynamic field between the natural, human and social sciences. The aim of presenting a feminist perspectives of caring was to demonstrate the centrality of the concepts of relationships, responsibility and duty in the constructions between conceptions of the self and conceptions of the other. As a result, this paper argued for the need of an expanded developmental theory that includes differences in the moral voice that embraces the feminist requirements of care. Such an inclusion seems essential, not only for explaining the development of care but also for understanding the characteristics and precursors of a caring conception that has been rooted in historical, cultural, social and political roles.

A caring practice cannot be adequately described as definite behaviors, actions, sentiments, or outcomes. Rather, what is perceived as a caring practice depends on the concerns that define the person's self and world. A feminist ethic of care remains a constructive approach to patient rights as it emphasizes responsibilities and relationships, the contexts of caring interdependencies, and allows patients to be active social players with a voice rather than passive recipients of care.

A feminist ethics suggest a conceptual deviation from the standpoint that care is impartial, individualistic and universal and instead argues that care and caring are determined by relationships, partiality, and notions of autonomy. These ideas encourage the theorization of social and cultural structuring of care and the public-private, moral-feminist distinctions that enable dominant discourse to re-conceptualize both care and the dichotomy of care. By maintaining feminism in the 'care' dialogue, possibilities and problems can be explored through the tensions that arise between them. Resisting the impulse to either dichotomize or synthesize the discourses of care ethics may provide some consideration to produce frameworks that highlights a political notion of care for all people.

\section{References}

1. Bottorff JL (1991) Nursing: a practical science of caring. ANS Adv Nurs Sci 14: 26-39.

2. Asp M, Fagerberg I (2005) Developing Concepts in Caring Science Based on a Lifeworld Perspective. International Journal of Qualitative Methods 4: 1-10.

3. Belenky M, Tarule J, Goldberger N (1986) Women's Ways of Knowing: The Development of Self, Voice, and Mind. Basic Books, New York.

4. Gilligan C (1982) In a Different Voice: Psychological Theory and Women's Development. Harvard University Press, Cambridge.

5. Jordan JV, Kaplan AG, Miller JB, Stiver IP, Surrey JL (1991) Women's growth in connection. Guilford Press, New York.

6. Miller JB (1986) What do we mean by relationships? Stone Center for Developmental Services and Studies, Wellesley College, Wellesley.

7. Kuhse H, Singer P, Rickard M (1998) Reconciling Impartial Morality And A Feminist Ethic Of Care. J Value Inq 32: 451-463.

8. Keohane RO (1989) International relations theory: Contributions of a feminis Standpoint. Millennium-Journal of International Studies 18: 245-253.

9. Morse JM, Bottorff J, Neander W, Solberg S (1991) Comparative analysis of conceptualizations and theories of caring. Image J Nurs Sch 23:119-126.

10. Leininger M (1988) Care the essence of nursing and health. Wayne State University Press, Michigan.

11. Sumner JF, Fisher WP Jr (2008) The Moral Construct of Caring in Nursing as
Communicative Action: The Theory and Practice of a Caring Science. ANS Adv Nurs Sci 31: E19-36.

12. Bowden $P$ (2001). An 'ethic of care' in clinical settings: encompassing 'feminine' and 'feminist' perspectives. Nursing philosophy 1: 36-49.

13. Tronto JC (1993) Moral boundaries: a political argument for an ethic of care. Routledge, New York.

14. Rytterström P, Cedersund E, Arman M (2009) Care and caring culture as experienced by nurses working in different care environments: a phenomenological-hermeneutic study. Int J Nurs Stud 46: 689-698.

15. Kittay EF, Meyers DT (1987) Remarks on the Sexual Politics of Reason: in Women and Moral Theory. Rowman \& Littlefiel, Totowa.

16. O'ReillyA (2010) Encyclopaedia of motherhood. (Vol 3), Sage Publications California.

17. Leininger MM (1991) Culture Care Diversity and Universality: A Theory of Nursing, National League for Nursing Press, New York.

18. Leininger M (1998) Special research report: dominant culture care (EMIC) meanings and practice findings from Leininger's theory. J Transcult Nurs 9: $45-48$.

19. Eagleton T (2000). The idea of culture. Blackwell, Oxford.

20. Houser R, Wilczenski F, Ham MA (2006) Culturally Relevant Ethical DecisionMaking In Counseling.Sage Publications, California.

21. Ruddick S (1995) Maternal Thinking: Toward a Politics of Peace. (2nd edn) Beacon Press, Boston

22. Jaggar A (1991) Feminist ethics: Problems, projects, prospects. In Feminist Ethics. University of Kansas, Lawrence.

23. Gustafson DL (2000) Best-laid plans: Examining contradictions between intent and outcome in a feminist collaborative research project. Qual Health Res 10 717-733.

24. Watson J (1990) Caring knowledge and informed moral passion. ANS Adv Nurs Sci 13:15-24.

25. Halwani R (2003) Care ethics and virtue ethics. Hypatia, 18: 161-192.

26. Nortvedt P, Hem MH, Skirbekk H (2011) The ethics of care: role obligations and moderate partiality in health care. Nurs Ethics 18: 192-200.

27. Larrabee MJ (1993)An ethic of care: Feminist and interdisciplinary perspectives. Routledge, New York.

28. Beauchamp TL, Childress JF (2001) Principles of Biomedical Ethics. (5th edn), Oxford University Press, Oxford.

29. Chirkov V (2003) Culture, personal autonomy and individualism: Their relationships and implications for personal growth and well-being: In Perspectives and progress in contemporary cross-cultural psychology. China Light Industry Press, Beijing.

30. Baumann H (2008) Reconsidering Relational Autonomy. Personal Autonomy for Socially Embedded and Temporally Extended Selves. Analyse \& Kritik, 30 445-468.

31. Friedman M (2000) Autonomy, social disruption and women: In MacKenzie C, Stoljar N (Eds) Relational autonomy, feminist perspectives on autonomy agency, and the social self. Oxford University Press, Oxford.

32. Friedman M (2003) Autonomy, gender, politics, New York.

33. Christman J (2004) Relational autonomy, liberal individualism, and the social constitution of selves. Philos Stud 117: 143-164.

34. Jordan JV, Hartling LM (2002) New developments in relational-cultural theory. In Ballou M, Brown LS (Eds) Rethinking Mental Health and Disorder. Guilford Press, New York.

35. Walker M (2004) How relationships heal. In M. Walker \& W.B. Rosen (Eds) How connections heal: Stories from relational-cultural therapy. The Guildford Press, New York.

36. Noddings $N$ (2010) Moral education in an age of globalization. Educational Philosophy and Theory 42: 390-396. 